www.jmscr.igmpublication.org

Impact Factor (SJIF): 6.379

Index Copernicus Value: 79.54

ISSN (e)-2347-176x ISSN (p) 2455-0450

crossrefDOI: https://dx.doi.org/10.18535/jmscr/v6i11.129

Journal Of Medical Science And Clinical Research

\title{
Restless leg syndrome in general population of an urban area in India
}

\author{
Authors \\ Harisudan $\mathrm{S}^{1}$, Soumya $\mathrm{PC}^{2}$, Prasanna $\mathrm{KB}^{3}$, Santosh Kumar $\mathrm{K}^{4}$ \\ ${ }^{1}$ Assistant Professor of medicine, Tagore Medical College and Hospital, Rathinamangalam, \\ Chennai -600127, India \\ ${ }^{2}$ Consultant Paediatrics, Calicut \\ ${ }^{3}$ Associate Professor of Medicine, Tagore Medical College and Hospital, Rathinamangalam, \\ Chennai -600127, India \\ ${ }^{4}$ CRRI, Tagore Medical College and Hospital, Rathinamangalam, Chennai -600127, India \\ Correspondence Author \\ Dr S. Harisudan \\ Assistant Professor of Medicine, Tagore Medical College and Hospital, Rathinamangalam, \\ Chennai -600127, India \\ Ph: +91-7200101771, Email: santosh10344@gmail.com
}

\begin{abstract}
Restless leg syndrome is a distressing condition characterised by an irresistible urge to move the legs owing to a creeping sensation of both legs. This disease is closely associated with parkinsonian disorders and other non-Parkinson's disorders and non-neurological illness such as diabetes mellitus. This study has been undertaken to study the clinical profile of restless leg syndrome and its association with various diseases. This was a cross sectional study which involved 40 patients. Patients have their history taken according to a Questionnaire and subjected to clinical examination. A section of the questionnaire was used to assess leg symptoms during sleep. In addition to these restless leg question, the questionnaire also included questions on self-rated general health status. The majority of the population is contributed by the Parkinson's Disease (16/40) contributing to $40 \%$. Other extrapyramidal symptoms such as tremors, dystonia contributed to $30 \%$ (12/40). Systemic illness such as Diabetes contributed to 25\% (10/40). Anaemia contributes for $12.5 \%$ (5/40). Alcohol contributed to 10\% (4/40). Other systemic illness such as CAD/ SHT/ CVA contributes to $27.5 \%$ (11/40). This study has stood in line with many of the previously conducted studies on Restless leg syndrome.

Keywords: Restless leg syndrome, Parkinson's disease, dementia, diabetes, anaemia.
\end{abstract}

\section{Introduction}

Restless leg syndrome (RLS) is a chronic distressing syndrome associated with an irresistible urge to move the legs owing to a creeping sensation of both $\operatorname{legs}^{[1]}$. Patients experience creeping, throbbing, aching and other unpleasant sensations felt during the night hours or while taking rest. This characteristically affects their sleep followed by excess day time somnolence and poor working capacity.

Restless leg syndrome also known as the Ekbom's disease is mainly a disease of the elderly and the 
$\operatorname{adults}^{[2]}$. However, it is known to occur in the other age groups too. There is a slight female preponderance and is more commonly noted among the western population. However recent reports have noted a seemingly increasing prevalence of RLS among the eastern and the Asian population ${ }^{[3]}$.

Though RLS starts in the lower limbs, it soon involves the other parts especially trunk and upper limbs. There may be extended periods of symptoms with lesser periods of remission or vice versa. Milder disease is associated with longer periods of remission ${ }^{[4]}$.

Progression of the manifestations can result in greater severity, more frequent attacks, greater provocation on taking rest, involvement of more night hours and more night times in a month. All these has resulted in poor recognition of this entity among the practising physician community, nonetheless RLS is now is being recognised as rather a serious disorder ${ }^{[5]}$.

This disease has been included under movement disorders and is closely associated with parkinsonian disorders. However, latest researches have found closer associations of restless leg syndrome with other non-Parkinson's disorders and non-neurological illness such as diabetes mellitus ${ }^{[6-8]}$.

Hence this study has been undertaken to study the clinical profile of restless leg syndrome and its association with various diseases.

\section{Materials and Methods \\ Study design and Participants}

This was a cross sectional study which involved 40 patients who attended the outpatient department of Tagore medical college, Rathinamangalam over a period of 12 months.

\section{Inclusion criteria}

- Any patient fitting into the criteria of Restless leg syndrome.

- Age group $>15$ years.

\section{Exclusion criteria}

- Pregnant women

- Patients with psychiatric illness

- Patients with cognitive decline

\section{Diagnosis of RLS and other clinical conditions}

Patients have their history taken according to a Questionnaire and subjected to clinical examination. A section of the questionnaire was used to assess leg symptoms during sleep. In addition to these restless leg question, the questionnaire also included questions on self-rated general health status. Further data were also collected on age, sex, height, weight, alcohol consumption, smoking habits, history of diabetes, exercise, income, education, and marital status. Patients were also subjected to investigations like complete blood count, renal function tests, blood sugar, urine analysis, imaging wherever indicated. The diagnosis of RLS was based on the minimal criteria provided by the International Classification of Sleep Disorders.

\section{Statistical analysis}

All the data were subjected to descriptive statistics using SPSS vs 19 software. The categorical variables are expressed in the form of frequencies and percentages.

\section{Results}

Among the total number of patients an elderly predominance was noted as in our case there were 24 patients greater than 50 years of age as compared to 16 patients who were below 50 years of age. This accounted for $60 \%$ of patients above 50years of age (Figure 1). 


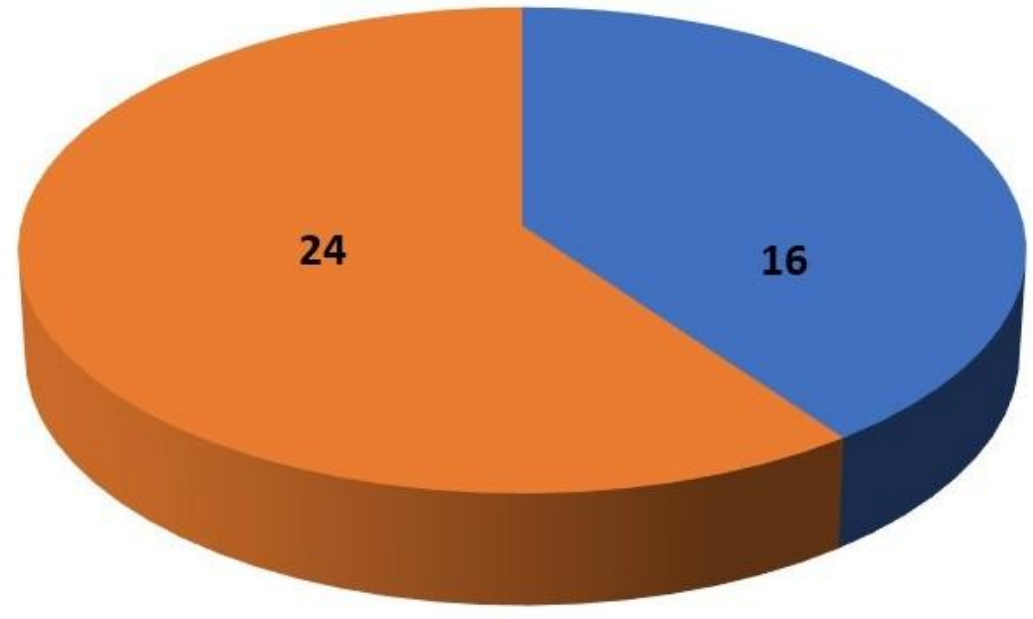

AGE $<50 Y R S$

AGE $>50 Y R S$

Figure 1: Distribution of patients of age below and above 50 years

Male predominance was noted in the study population, males contributed to $62.5 \%$ of the population $(25 / 40) 37.5 \%$ of the population was contributed by the female gender (Figure 2).

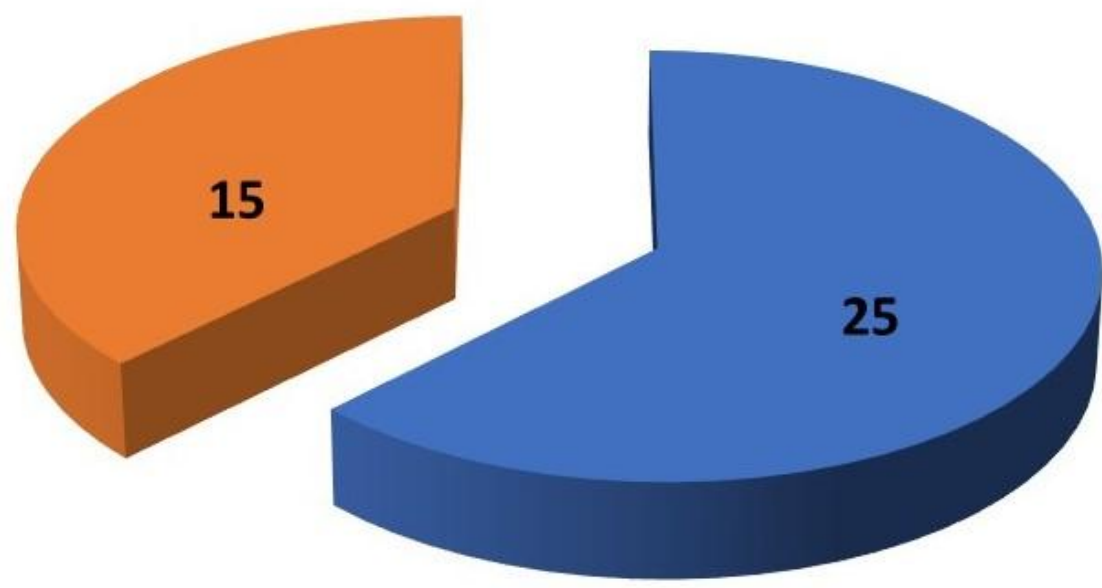

MALES

FEMALES

Figure 2: Gender distribution of patients

The majority of the population is contributed by the Parkinson's Disease (16/40) contributing to $40 \%$. Other extrapyramidal symptoms such as tremors, dystonia contributed to $30 \%(12 / 40)$. Systemic illness such as Diabetes contributed to $25 \%$ (10/40). Anaemia contributes for $12.5 \%$
(5/40). Alcohol contributed to $10 \%$ (4/40). Other systemic illness such as CAD/ SHT/ CVA contributes to $27.5 \%$ (11/40) (Table 1). Some patients showed single illness and few of them showed more than one illness.

Table 1: Distribution of general illness among the RLS patients

\begin{tabular}{|l|c|c|}
\hline S. No. & Illness seen among the RLS patients & $\begin{array}{c}\text { Number of Patients } \\
(\mathbf{N = 4 0 )}\end{array}$ \\
\hline 1. & Parkinson's Disease & $16(40 \%)$ \\
\hline 2. & Diabetes & $10(25 \%)$ \\
\hline 3. & Anaemia & $5(12.5 \%)$ \\
\hline 4. & Alcohol consumption & $4(10 \%)$ \\
\hline 5. & Extrapyramidal symptoms such as tremors, dystonia & $12(30 \%)$ \\
\hline 6. & Other systemic illness such as CAD/ SHT/ CVA & $11(27.5 \%)$ \\
\hline
\end{tabular}


The distribution of Parkinson related symptoms and dementia among these patients were analysed. The fronto temporal dementia was present in 4/40 patients. There were two patients with Progressive supranuclear palsy and one each of Cortico basal degeneration and Alzhiemer's dementia. Among

Table 2: Distribution of Parkinson related symptoms and dementia

\begin{tabular}{|l|c|c|}
\hline S. No. & Symptoms related to Parkinson's disease and dementia & Number of Patients \\
\hline 1. & Fronto temporal dementia & $4(10 \%)$ \\
\hline 2. & Progressive supranuclear palsy & $2(5 \%)$ \\
\hline 3. & Cortico basal degeneration & $1(2.5 \%)$ \\
\hline 4. & Alzhiemer's dementia & $1(12.5)$ \\
\hline
\end{tabular}

The distribution of other extrapyramidal involuntary movements was also seen. Essential tremors were noted in two patients contributing to $7.2 \%(2 / 28)$ among all extrapyramidal symptoms. One had Painful Leg Moving Toes and another had Paroxysmal Kinesiogenic Dyskinesia. Each contributing to $3.6 \%$ of all extrapyramidal features (Table 3).

Table 3: Distribution of important extrapyramidal involuntary movements

\begin{tabular}{|l|c|c|}
\hline S. No. & $\begin{array}{c}\text { Extrapyramidal } \\
\text { involuntary movements }\end{array}$ & $\begin{array}{c}\text { Number of } \\
\text { Patients }\end{array}$ \\
\hline 1. & Extrapyramidal symptoms & $2(7.2 \%)$ \\
\hline 2. & Painful leg moving toes & $1(3.6 \%)$ \\
\hline 3. & $\begin{array}{c}\text { Paroxysmal kinesiogenic } \\
\text { dyskinesia }\end{array}$ & $1(3.6 \%)$ \\
\hline
\end{tabular}

MRI Brain revealing Bilateral Basal Ganglia hyperintensities in $32.5 \%$ (13/40), Cortical/ capsular/Ganglionic infarcts noted in 10\% (4/40). Small vessel disease, and PSP findings noted in one patient. Two patients had cortical atrophy out of which one had diffuse cortical atrophy and one had fronto temporo atrophy (Table 4).

Table 4: Distribution of MRI findings among the patients

\begin{tabular}{|l|c|c|}
\hline S. No. & MRI findings & $\begin{array}{c}\text { Number of } \\
\text { Patients }\end{array}$ \\
\hline 1. & $\begin{array}{c}\text { Bilateral Basal Ganglia } \\
\text { hyperintensity }\end{array}$ & $13(32.5 \%)$ \\
\hline 2. & $\begin{array}{c}\text { Cortical/capsular/Ganglionic } \\
\text { infarcts }\end{array}$ & $4(10 \%)$ \\
\hline 3. & Small vessel disease & $1(2.5 \%)$ \\
\hline 4. & PSP & $1(2.5 \%)$ \\
\hline 5. & Cortical atrophy & $2(5 \%)$ \\
\hline
\end{tabular}

the extrapyramidal symptoms and dementia $50 \%$ is contributed by Frontotemporal dementia, 25\% contributed by Progressive supranuclear palsy. $12.5 \%$ each by Alzheimer's and Cortico-basal degeneration (Table 2).

Restless leg syndrome complaints are noted for varied periods of time among the patients. Around $40 \%$ had the duration between 1-2 yrs. $30 \%$ had been suffering between 6 months to one year. $12.5 \%$ had the onset either less than 6 months and more than 2 years with the least being 3 months and the longest being 3 years.

\section{Discussion}

Restless leg syndrome is an under reported condition but which is being very commonly discovered among the general population. In our study which included 40 patients who fulfilled the diagnostic questionnaire to diagnose restless leg syndrome, we noticed that there was a greater association of this condition to other extrapyramidal conditions more commonly Parkinson's disease. In a similar study conducted by Bliwise et al., $20.8 \%$ prevalence of parkinsonian features among the patients with Restless leg syndrome was observed ${ }^{[9]}$. Less commonly they were associated with other extrapyramidal conditions such as essential tremors, paroxysmal kinesiogenic dyskinesia etc.

This syndrome was also noted in patients with dementias such as fronto temporal dementia and alzheimer's dementia though their association was relatively rare which was not reported in previous studies. RLS was also noted in patients with Parkinson plus syndromes like Progressive supranuclear palsy and Cortico basal degeneration. Moccia et al. has reported a varied prevalence of Restless leg syndrome among patients with Progressive supranuclear palsy 
ranging between $3-58 \%^{[10]}$. Systemic diseases noted to have association with RLS includes diabetes, alcoholic neuropathy and anaemia due to various causes.

Age related distribution was found to be more common among those above $50 \mathrm{yrs}$ of age $(60 \%)$ as compared to those below $50 \mathrm{yrs}$ of age. Most of the studies have demonstrated a clear elderly predominance in the prevalence of Restless leg syndrome. This was similar to the findings noted in the study conducted by Ceglia ${ }^{[11]}$.

As mentioned by Wali et al. a clear male predominance was noted among the sufferers in our study ${ }^{[12]}$. The elderly predominance could also attribute to the associated chronic disease conditions such as diabetes and chronic kidney disease found in close association with this syndrome.

Majority of the patients complained of abnormal sensation persisting more during the night and evening hours. The next common time being the early morning hours before getting up from bed. A few of them had this complaint persisting throughout the day. The least common timing among them being the afternoon hours. None of the studies conducted prior could show a significant correlation between the hours of the day and the severity of the symptoms though they have mentioned a clear association with respect to the timing of taking rest.

Some of the patients with restless leg syndrome showed abnormalities on brain imaging, the most common among them being bilateral basal ganglia hyper intensities. A few also had evidence of small vessel disease and volume loss. This kind of finding wherein a predominant basal ganglia abnormality was described by Bliwise et al ${ }^{[9]}$.

\section{Conclusion}

This study has stood in line with many of the previously conducted studies on Restless leg syndrome. The age, gender factors and the systemic association and its association with extrapyramidal conditions were similar to what was reported in the previous studies. However, the greater frequency of MRI findings in these patients have not been reported previously. Moreover, this kind of study on Restless leg syndrome has not been widely done in a south Indian set up previously, which of course adds on to the value to this study.

\section{References}

1. Krueger BR. Restless legs syndrome and periodic movements of sleep. Mayo Clin Proc. 1990; 65(7):999-1006.

2. Ekbom K, Ulfberg J. Restless legs syndrome. J Intern Med. 2009 Nov. 266(5):419-31.

3. American Psychiatric Association. Diagnostic and Statistical Manual of Mental Disorders, Fifth Edition. $5^{\text {th }}$. Arlington, VA: American Psychiatric Association; 2013. 410-3.

4. Gamaldo CE, Earley CJ. Restless legs syndrome: a clinical update. Chest. 2006 Nov. 130(5):1596-604.

5. Ferreri F, Rossini PM. Neurophysiological investigations in restless legs syndrome and other disorders of movement during sleep. Sleep Med. 2004; 5(4):397-9.

6. Turkdogan D, Bekiroglu N, Zaimoglu S. A prevalence study of restless legs syndrome in Turkish children and adolescents. Sleep Med. 2011;12(4):315-21.

7. Taşdemir $M$, Erdoğan $H$, Börü UT, Dilaver E, Kumaş A. Epidemiology of restless legs syndrome in Turkish adults on the western Black Sea coast of Turkey: A door-to-door study in a rural area. Sleep Med.2010; 11:82-86.

8. Bhowmik D, Bhatia M, Tiwari S et al. Low prevalence of restless legs syndrome in patients with advanced chronic renal failure in the Indian population: a casecontrolled study. Ren Fail2004; 26 (1): 6972.

9. Bliwise DL, Freeman A, Ingram CD, et al. Randomized, double-blind, placebocontrolled, short-term trial of ropinirole in 
restless legs syndrome. Sleep Med. 2005; 6:141-7.

10. Moccia $\mathrm{M}$ et al. Restless legs syndrome is a common feature of adult celiac disease. Mov Disord. 2012; 25(7):8877-881.

11. Ceglia L. Vitamin D and Its Role in Skeletal Muscle. Curr Opin Clin Nutr Metab Care. 2009; 12:628-633.

12. Wali S, Shukr A, Boudal A, Alsaiari A, Krayem A. The effect of vitamin D supplements on the severity of restless legs syndrome. Sleep and Breathing. 2014; 23: 301-6. 